DOI: $10.5800 /$ GT-2022-13-2s-0630

\title{
A RESPONSE OF THE "RESERVOIR-WELL" SYSTEM TO DISTANT EARTHQUAKES
}

\author{
E.M. Gorbunova $\oplus^{凶}$, A.N. Besedina $\odot$, I.A. Sanina $\odot$, N.L. Konstantinovskaya $\odot$
}

Sadovsky Institute of Geospheres Dynamics, Russian Academy of Sciences, 38-1 Leninsky Ave, Moscow 119334, Russia

ABSTRACT. The results of joint processing of hydrogeological and seismic data obtained at the Large-Scale Research Facilities "Mid-Latitude Geophysical Observation Complex "Mikhnevo" for a 12-year observation period are presented in the article. Responses of the "reservoir-well" system to the passage of seismic waves from distant earthquakes with magnitudes of 6.3-9.0, recorded at the epicentral distances from 1863 to $16507 \mathrm{~km}$, have been identified in the database. Maximum values of groundwater level variations and ground velocity under seismic impact have been determined. The power-law dependence of the levels amplitudes of confined and weakly confined aquifers on the maximum vertical ground velocity has been established. A spectral analysis of 6-hour intervals (3 hours before and 3 hours after earthquakes) of seismic and hydrogeological data was performed. The frequencies corresponding to the maximum values of ground velocity and groundwater level variations were determined in the normalized spectra. The intervals within which the extremes of the hydrogeological responses are traced at background values of the ground velocity are identified in the low-frequency range. The amplitude-frequency characteristics of the "reservoir-well" systems differ under seismic impacts at epicentral distances up to $4901 \mathrm{~km}$. The responses of the systems to earthquakes at epicentral distances of 11024-14026 km are similar.

KEYWORDS: "reservoir-well" system; distant earthquake; hydrogeological response; ground velocity; amplitude spectrum; dominant frequency; precision monitoring; seismic measurements

FUNDING: The work was done in accordance with the state assignments of the Ministry of Science and Higher Education of the Russian Federation 1021052706247-7-1.5.4 (FMWN-2022-0015) and 1021052706257-4-1.5.4 (FMWN2022-0017).

\section{SHORT COMMUNICATION}

Correspondence: Ella M. Gorbunova, emgorbunova@bk.ru
Received: December 6, 2021

Revised: December 22, 2021

Accepted: December 30, 2021

FOR CITATION: Gorbunova E.M., Besedina A.N., Sanina I.A., Konstantinovskaya N.L., 2022. A Response of the "Reservoir-Well" System to Distant Earthquakes. Geodynamics \& Tectonophysics 13 (2s), 0630. doi:10.5800/GT-2022-13-2s-0630 


\title{
РЕАКЦИЯ СИСТЕМ «ПЛАСТ - СКВАЖИНА» НА УДАЛЕННЫЕ ЗЕМЛЕТРЯСЕНИЯ
}

\author{
Э.М. Горбунова, А.Н. Беседина, И.А. Санина, Н.Л. Константиновская
}

Институт динамики геосфер РАН им. Академика М.А. Садовского, 119334, Москва, Ленинский пр-т, 38/1, Россия

\begin{abstract}
АННОТАЦИЯ. В статье представлены результаты совместной обработки гидрогеологических и сейсмических данных, полученных на уникальной научной установке «Среднеширотный комплекс геофизических наблюдений "Михнево"» ИДГ РАН за 12-летний период наблюдений. В сформированной базе данных выделены отклики системы «пласт - скважина» на прохождение сейсмических волн от удаленных землетрясений с магнитудой 6.3-9.0, зарегистрированных на эпицентральных расстояниях от 1863 до 16507 км. Определены максимальные значения вариаций уровня подземных вод и скорости смещения грунта при сейсмическом воздействии. Установлена степенная зависимость амплитуд уровней напорного и слабонапорного водоносных горизонтов от максимальной скорости смещения грунта по вертикальной компоненте. Выполнен спектральный анализ выборки 6-часовых интервалов (3 ч до и 3 ч после землетрясения) сейсмических и гидрогеологических данных. На нормированных спектрах определены частоты, соответствующие максимальным значениям скорости смещения грунта и вариациям уровня подземных вод. В низкочастотной области выделены интервалы, в пределах которых прослежены экстремумы гидрогеологических откликов при фоновых значениях скорости смещения грунта. Амплитудно-частотные характеристики систем «пласт - скважина» при сейсмическом воздействии на эпицентральных расстояниях до 4901 км различаются. При регистрации землетрясений на эпицентральных расстояниях 11024-14026 км реакция систем подобна.
\end{abstract}

КЛЮЧЕВЫЕ СЛОВА: система «пласт - скважина»; удаленное землетрясение; гидрогеологический отклик; скорость смещения грунта; амплитудный спектр; доминирующая частота; прецизионный мониторинг; сейсмические измерения

ФИНАНСИРОВАНИЕ: Работа выполнена в рамках государственных заданий Минобрнауки РФ № $1021052706247-$ 7-1.5.4 (FMWN-2022-0015) и № 1021052706257-4-1.5.4 (FMWN-2022-0017).

\section{1. ВВЕДЕНИЕ}

За последние десятилетия в связи с широким использованием высокоточных датчиков уровня и давления подземных вод в разных регионах мира зарегистрированы разнообразные гидрогеологические эффекты от землетрясений [Kopylova, Boldina, 2020; Besedina et al., 2016; Brodsky et al., 2003; Shalev et al., 2016; Shi et al., 2015; Xiang et al., 2019]. Реакция системы «пласт скважина» на сейсмическое воздействие рассматривается в качестве индикатора динамического деформирования водонасыщенного коллектора. В результате систематизации полученных результатов выделены основные типы гидрогеологических откликов: предвестники, косейсмические и постсейсмические эффекты в виде вариаций уровня, скачкообразного или плавного, подъема или снижения уровня, которые могут сопровождаться дополнительной осцилляцией [Sun et al., 2015].

На основе спектрального анализа исследуется взаимосвязь между вариациями уровня и скоростью смещения грунта [Shin et al., 2013]. Для периодов менее 60 с отмечена высокая корреляция между сейсмическими и гидрогеологическими вариациями. Различие амплитудных спектров уровня в скважинах и смещения грунта в диапазоне периодов 20-30 с регистрировалось на эпицентральных расстояниях свыше 9500 км [Sun et al., 2018]. При периодах более 60 с могут проявляться постсейсмические эффекты [Sun et al., 2015].
За 12-летний период синхронных гидрогеологических и сейсмических измерений, проводимых на уникальной научной установке «Среднеширотный комплекс геофизических наблюдений "Михнево"» (УНУ СКГН «Михнево») ИДГ РАН (Московская область), впервые в асейсмичном регионе зарегистрированы гидрогеологические отклики более чем на 60 землетрясений, произошедших на эпицентральных расстояниях от 1863 до 16507 км. Основная задача настоящей работы - анализ выделенных вариаций уровней слабонапорного и напорного водоносных горизонтов, связанных с прохождением сейсмических волн от удаленных землетрясений, для определения амплитудно-частотных характеристик систем «пласт - скважина».

\section{2. ХАРАКТЕРИСТИКА ОБЪЕКТА ИССЛЕДОВАНИЙ}

Геологическое строение экспериментального полигона ИДГ РАН характеризуется четкой тектонической двухъярусностью. Нижний структурный этаж - кристаллический фундамент - вскрыт Серпуховской скважиной на глубине 1310 м. Верхний структурный этаж сложен терригенно-осадочной толщей пород, залегающей с угловым несогласием на верхнепротерозойских образованиях.

Верхняя зона активного водообмена мощностью 200-250 м приурочена к моноклинально залегающей толще терригенно-карбонатных пород с региональным уклоном на северо-восток до 0.001-0.003. 
Водовмещающие породы сложены известняками, неравномерно трещиноватыми с подчиненными прослоями доломита, мергеля, глины.

В пределах территории исследований преимущественное распространение получают два водоносных горизонта. Слабонанапорный каширский водоносный горизонт среднего карбона вскрыт в интервале 46.256.6 м. В кровле слабонапорного горизонта залегают прослои мергеля, глины. Величина напора над кровлей не превышает метра. От нижезалегающего напорного водоносного горизонта - алексинско-протвинского нижнего карбона - отделен верейскими глинами среднего карбона мощностью 19.5 м. Наличие регионального водоупора определяет гидростатический разрыв уровней верхнего слабонапорного и нижнего напорного водоносных горизонтов. Уровень верхнего горизонта устанавливается на глубине 46.2 м, нижнего на 66.7 м. Величина напора алексинско-протвинского водоносного горизонта, пройденного в интервале 92-115 м, за период наблюдений 2007-2020 гг. изменялась от 20.8 до 26.5 м. Обводненность пород с глубиной уменьшается. Водопроводимость верхнего каширского водоносного горизонта составляет $15 \mathrm{~m}^{2} /$ сут, нижнего алексинско-протвинского - не превышает $3 \mathrm{~m}^{2} /$ сут.

Режим слабонапорного каширского горизонта техногенно нарушен из-за повсеместной эксплуатации многочисленными скважинами и колодцами. Тем не менее в вариациях уровня прослеживается годовая цикличность в виде интенсивного подъема уровня в паводок с амплитудами от 0.9 м (весна 2020 г.) до 1.9 м (весна 2017 г.). В напорном алексинско-протвинском водоносном горизонте сезонные вариации уровня более продолжительные. Максимальная амплитуда подъема уровня до 3.1 м установлена весной 2016 г. Минимально низкое положение пьезометрической поверхности отмечено на протяжении всего 2011 г. и связано с предшествующим маловодным (засушливым) 2010 г.

\section{3. МЕТОДЫ ИЗМЕРЕНИЙ И ОБРАБОТКИ ЭКСПЕРИМЕНТАЛЬНЫХ ДАННЫХ}

Высокоточные наблюдения за вариациями уровня слабонапорного и напорного водоносных горизонтов выполняются в двух скважинах глубиной 60 и 115 м соответственно с использованием датчиков LMP308i, частота опроса 1 Гц, точность измерений 1.7 мм. Сейсмическая регистрация ведется широкополосными сейсмометрами STS-2 и CM-3-E с частотой опроса 100 Гц, установленными в шахте на глубине 20 м и входящими в состав малоапертурной группы УНУ СКГН «Михнево». При сопоставлении с гидрогеологическими данными частота дискретизации сейсмических записей приведена к 1 Гц.

По результатам предварительной обработки базы данных экспериментально установлен нижний порог скорости смещения грунта ( $\geq 0.05$ мм/с) при регистрации землетрясений в вариациях уровня подземных вод, который использован для формирования выборки 6-часовых интервалов гидрогеологических и сейсмических записей. В группах поверхностных волн, выделенных на сейсмограммах скорости смещения грунта и в уровне слабонапорного и напорного горизонтов, определены максимальные значения амплитуд, измеренные между последовательным максимумом и минимумом в скользящем окне длительностью 72 с и перекрытием $50 \%$.

По сейсмическим и гидрогеологическим данным за три часа до прихода Р-волны на сейсмический датчик УНУ СКГН «Михнево» и через три часа после рассчитывалось отношение модулей спектров и спектральная плотность мощности скорости смещения грунта и колебаний уровня воды. Наряду со стандартными методами обработки данных для определения параметров зарегистрированных сигналов и анализа спектров дополнительно рассматривается амплитудно-частотная характеристика системы «пласт - скважина» как отношение амплитудных спектров гидрогеологических откликов слабонапорного и напорного водоносных горизонтов (мм) к скорости смещения грунта (мм/с).

\section{4. РЕЗУЛЬТАТЫ ИЗМЕРЕНИЙ И ОБСУЖДЕНИЕ}

За период наблюдений 2010-2019 гг. сформирована база данных синхронной регистрации удаленных землетрясений на УНУ СКГН «Михнево». В напорном водоносном горизонте прослежены гидрогеологические отклики на землетрясения М 7.1-9.0, произошедшие на эпицентральных расстояниях от 1864 до 14862 км. В слабонапорном водоносном горизонте гидрогеологические эффекты выделены от землетрясений М 6.2-8.3 на эпицентральных расстояниях от 1863 до 16507 км (рис. 1).

При скорости смещения грунта от 0.05 до 3.78 мм/с амплитуды гидрогеологических откликов слабонапорного водоносного горизонта варьируются от 2.1 до 110.6 мм, напорного - от 2.2 до 41.5 мм. Зависимость динамических колебаний уровня подземных вод от скорости смещения грунта аппроксимируется степенной функцией. Для слабонапорного водоносного горизонта регрессионная зависимость характеризуется более высоким коэффициентом детерминации по сравнению с напорным. Амплитуды гидрогеологических откликов слабонапорного и напорного горизонтов в среднем различаются на порядок в диапазоне зарегистрированной скорости смещения грунта 0.6-1.3 мм/с.

Подобие волновых форм вариаций уровня подземных вод и сейсмических колебаний в группе поверхностных волн от удаленных землетрясений может проявляться как ограниченно только в высокочастотной (период <60 c) или низкочастотной области (период $>60$ c), так и в широком диапазоне частот [Gorbunova et al., 2018]. На нормированных спектрах экстремумы косейсмических вариаций уровня и смещения грунта преимущественно совпадают, реже - смещены в область низких частот [Batukhtin et al., 2020].

Постсейсмический эффект в виде плавного подъема уровня напорного водоносного горизонта отмечен 


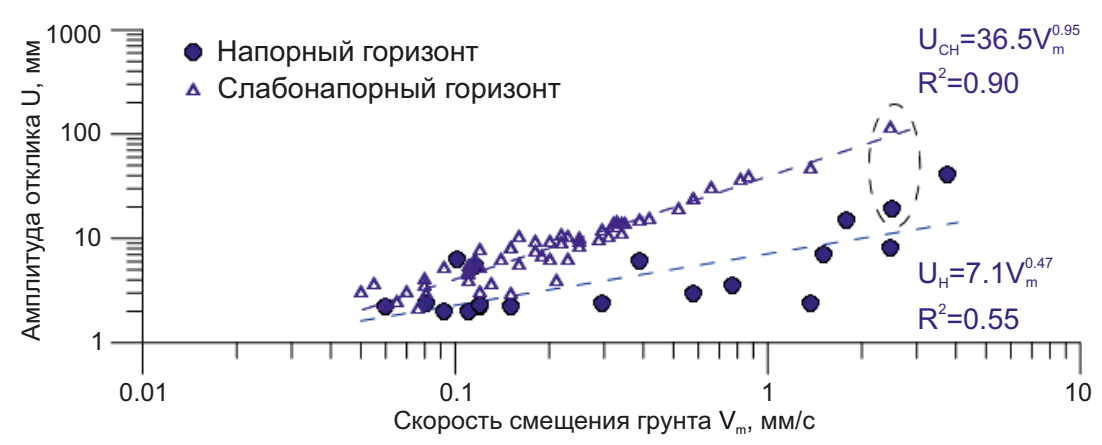

Рис. 1. Зависимость амплитуд уровней напорного и слабонапорного водоносных горизонтов от максимальной скорости смещения грунта по вертикальной компоненте от удаленных землетрясений на территории геофизической обсерватории ИДГ РАН (пунктиром выделены отклики на землетрясение Чьяпас, Мексика, 08.09.2017 г., М 8.3).

Fig. 1. Relationship between the amplitudes of groundwater heads in a confined or weakly confined aquifer and the maximum vertical ground velocity from earthquakes at the territory of geophysical observatory IDG RAS (dotted ellipse identifies the responses to the September 8, 2017 M 8.3 earthquake in Chiapas, Mexico).
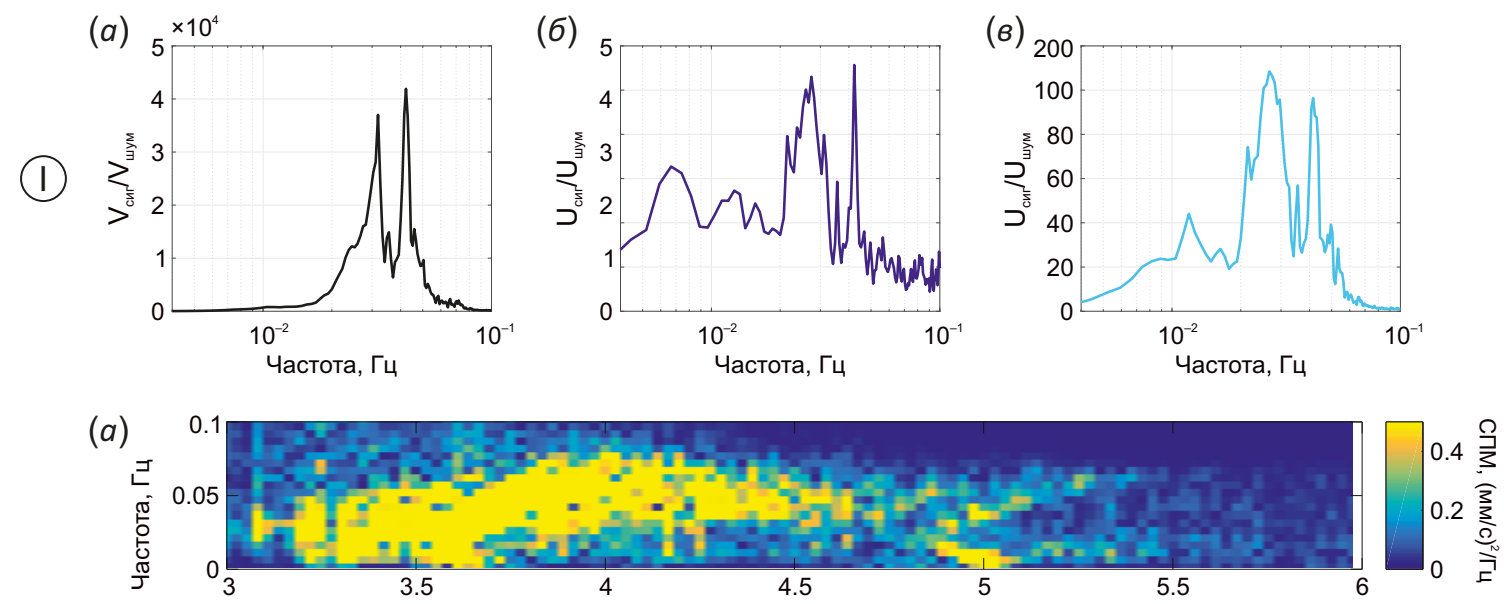

(II)
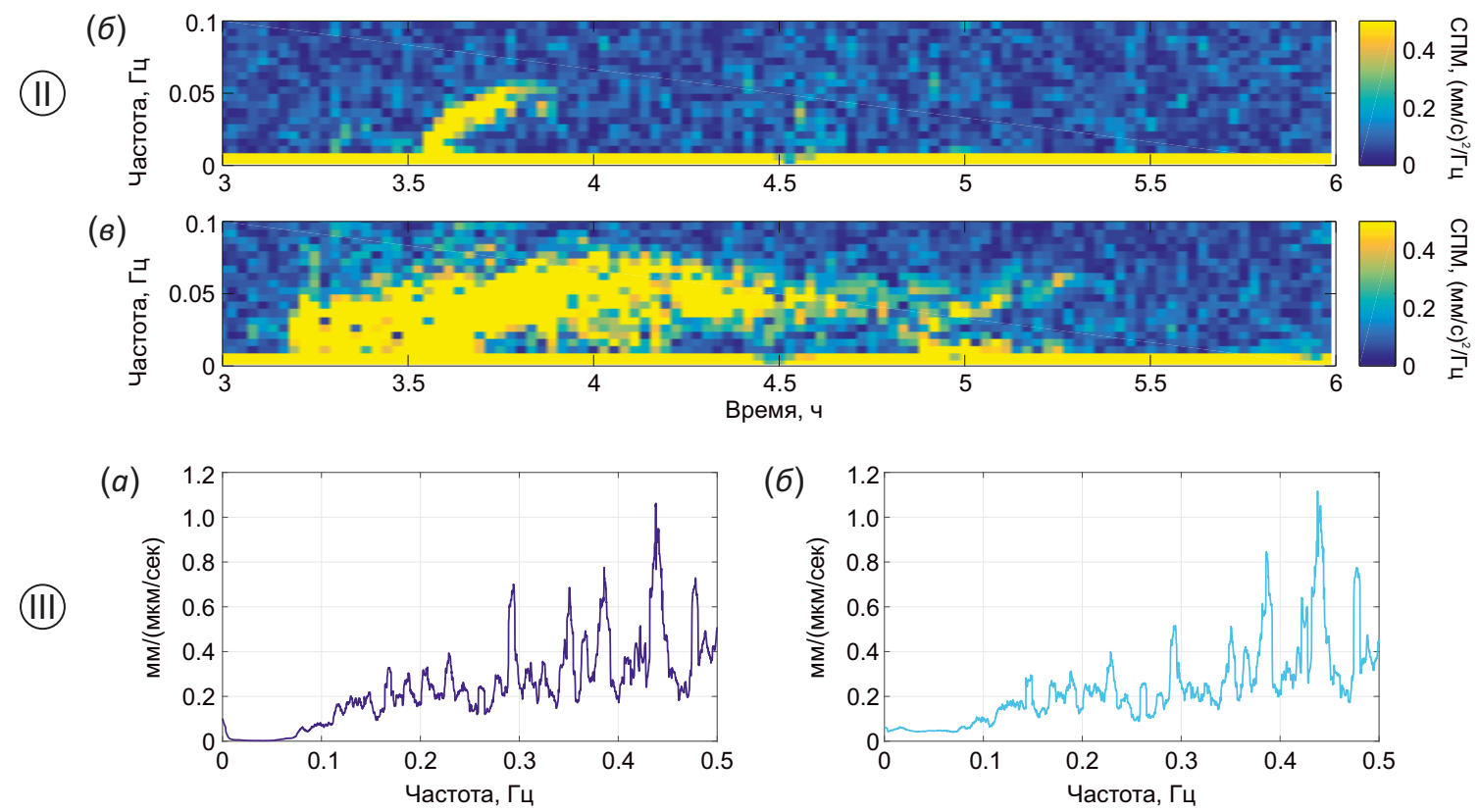

Рис. 2. Нормированные спектры (I), спектрограммы (II) и амплитудно-частотные характеристики (III) систем «пласт скважина» при землетрясении Чьяпас, Мексика, 08.09.2017 г., М 8.3 ((a) - скорость смещения грунта, (б, в) - уровни водоносных горизонтов: (б) - напорного, (в) - слабонапорного).

Fig. 2. Normalized spectra (I), spectrograms (II) and amplitude-frequency characteristics (III) of the "reservoir - well" systems for the September 8, 2017 M 8.3 earthquake in Chiapas, Mexico ((a) - ground velocity, $(\sigma, 8)$ - groundwater heads in aquifers: (б) - confined, (в) - weakly confined). 
в единичных случаях при скорости смещения более 1.7 мм/с от удаленных землетрясений М 8.2-9.0, произошедших 27.02.2010 г. у побережья Чили, 11.03.2011 г. в г. Тохоку, Япония, 11.04.2012 г. на побережье Северной Суматры и 08.09.2017 г. вблизи побережья Чьяпас, Мексика. Нормированные спектры вариаций уровня и скорости смещения грунта вышеперечисленных землетрясений при рассмотрении отношения сигнал/шум различаются. Например, при катастрофическом землетрясении 08.09.2017 г. максимальные значения скорости смещения грунта выделяются на частоте 0.032 и 0.041 Гц, уровня напорного и слабонапорного водоносных горизонтов - в диапазоне 0.028 и 0.041 Гц (рис. 2, I). В низкочастотной области в интервалах частот 0.0060.008 Гц в вариациях уровня напорного горизонта и 0.01-0.02 Гц напорного и слабонапорного горизонтов проявляются дополнительные экстремумы, которые отсутствуют в скорости смещения грунта.

На спектрограммах вариации спектральной плотности мощности (СПМ) скорости смещения грунта и уровня слабонапорного горизонта подобны и прослежены в диапазоне 0.010-0.075 Гц, характерном для поверхностных волн, в течение 2 ч, в отличие от менее интенсивной и более кратковременной (до 0.5 ч) СПМ напорного горизонта в диапазоне 0.01-0.05 Гц (рис. 2, II). Несмотря на различия в реакциях слабонапорного и напорного водоносных горизонтов на прохождение сейсмических волн от землетрясения 08.09.2017 г., отмеченные на нормированных спектрах и спектрограммах, амплитудно-частотные характеристики рассматриваемых систем «пласт - скважина» идентичны и характеризуются одинаковой чувствительностью $>0.5$ мм/(мкм/с) на частотах 0.29, 0.35, $0.38,0.44$ и 0.47 Гц (рис. 2, III). Подобная реакция систем «пласт - скважина» прослежена на землетрясение 16.09.2015 г. вблизи Чили на эпицентральном расстоянии 14026 км.

Чувствительность систем напорного и слабонапорного водоносных горизонтов на землетрясения, произошедшие на эпицентральных расстояниях от 2315 до 4901 км, различается. Экстремумы слабонапорного горизонта с амплитудами $>1$ мм/(мкм/с) проявились в широком диапазоне частот от 0.36-0.38 до 0.48 Гц при мелкофокусных землетрясениях 28.09.2013 г. в Пакистане и 12.05.2015 г. в Непале. Экстремум напорного горизонта с амплитудой $>0.5$ мм/(мкм/с) при среднефокусном землетрясении 16.04.2013 г. в Пакистане отмечен только на частоте 0.49 Гц по вертикальной компоненте, по горизонтальным - на частоте 0.37 и 0.43 Гц.

\section{5. ЗАКЛЮЧЕНИЕ}

На основе обработки базы данных, сформированной за многолетний период измерений, проводимых на УНУ СКГН «Михнево», исследована реакция системы «пласт - скважина» на сейсмическое воздействие. Определены амплитуды вариаций слабонапорного и напорного водоносных горизонтов, и установлена степенная зависимость зарегистрированных гидрогеологических эффектов от максимальной скорости смещения грунта.

В платформенных условиях на территории ГФО «Михнево» наряду с косейсмическими выделены постсейсмические эффекты, которые соответствуют необратимому изменению структуры трещинно-порового пространства Для таких событий установлены интервалы частот, которые характеризуются смещением экстремумов гидрогеологических откликов в область низких частот относительно максимальных значений сейсмических сигналов.

Подземные воды могут являться как индикатором состояния флюидонасыщенного коллектора, так и реагентом, провоцирующим изменение структуры коллектора трещинно-порового типа. Полученные новые результаты, вероятно, приближают нас к пониманию механизма реакции флюидонасыщенного коллектора на факторы различного типа, в частности на условия проявления постсейсмических изменений уровня подземных вод.

\section{6. ЗАЯВЛЕННЫЙ ВКЛАД АВТОРОВ / CONTRIВUTION OF THE AUTHORS}

Все авторы внесли эквивалентный вклад в подготовку публикации.

The authors contributed equally to this article.

\section{7. КОНФЛИКТ ИНТЕРЕСОВ / CONFLICT OF INTERESTS}

Авторы заявляют об отсутствии у них конфликта интересов. Все авторы прочитали рукопись и согласны с опубликованной версией.

The authors have no conflicts of interest to declare. All authors have read and agreed to the published version of the manuscript.

\section{8. ЛИТЕРАТУРА / REFERENCES}

Batukhtin I.V., Besedina A.N., Gorbunova E.M., Petukhova S.M., 2020. Dynamic Deformation of Fluid-Saturated Collectors by Precision Hydrogeological Monitoring at "Mikhnevo" Geophysical Observatory. Processes in Geomedia 4 (26), 867-876 (in Russian) [Батухтин И.В., Беседина А.Н., Горбунова Э.М., Петухова С.М. Динамическое деформирование флюидонасыщенных коллекторов по данным прецизионного гидрогеологического мониторинга на территории геофизической обсерватории «Михнево» // Процессы в геосредах. 2020. 4 (26). C. 867-876].

Besedina A., Vinogradov E., Gorbunova E., Svintsov I., 2016. Chilen Earthquakes: Aquifer Responses at the Russian Platform. Pure and Applied Geophysics 173, 321-730. http://dx.doi.org/10.1007/s00024-016-1256-5.

Brodsky E.E., Roeloffs E., Woodcock D., Gall I., Manga M., 2003. A Mechanism for Sustained Groundwater Pressure Changes Induced by Distant Earthquakes. Journal of Geophysical Research: Solid Earth 108 (B8). http://dx.doi.org/ 10.1029/2002JB002321. 
Gorbunova E.M., Besedina, A.N., Vinogradov E.A., 2018. Dynamics of Deformation in the Fluid-Saturated Collector from Precision Monitoring of Groundwater Level. In: Dynamic Processes in Geospheres. Collection of Scientific Papers of the Institute of Mining RAS. Iss. 10. Grafiteks, Moscow, p. 74-83 (in Russian) [Горбунова Э.М., Беседина А.Н., Виноградов Е.А. Динамика деформирования флюидонасыщенного коллектора по данным прецизионного мониторинга уровня подземных вод // Динамические процессы в геосферах: Сборник научных трудов ИГд PAН. М.: Графитекс, 2018. Вып. 10. C. 74-83]. https://doi. org/10.26006/IDG.2018.10.20178.

Kopylova G.N., Boldina S.V., 2020. Effects of Seismic Waves in Water Level Changes in a Well: Empirical Data and Models. Izvestiya, Physics of the Solid Earth 56, 530-549. https://doi.org/10.1134/S1069351320030039.

Shalev E., Kurzon I., Doan M.-L., Lyakhovsky V., 2016. Sustained Water-Level Changes Caused by Damage and Compaction Induced by Teleseismic Earthquakes. Journal of Geophysical Research: Solid Earth 121 (7), 4943-4954. https://doi.org/10.1002/2016JB013068.

Shi Z., Wang G., Manga M., Wang C.-Y., 2015. Mechanism of Co-Seismic Water Level Change Following Four Great
Earthquakes - Insights from Co-Seismic Responses throughout the Chinese Mainland. Earth and Planetary Science Letters 430, 66-74. http://dx.doi.org/10.1016/j.epsl.20 15.08.012.

Shin D.C-F., Wu Y.-M., Chang C.-H., 2013. Significant Coherence for Groundwater and Rayleigh Waves: Evidence in Spectral Response of Groundwater Level in Taiwan Using 2011 Tohoku Earthquake, Japan. Journal of Hydrology 486, 57-70. http://dx.doi.org/10.1016/j.jhydrol.20 13.01.013.

Sun X., Wang G., Yang X., 2015. Coseismic Response of Water Level in Changping Well, China, to the Mw 9.0 Tohoku Earthquake. Journal of Hydrology 531 (3), 1028-1039. http://dx.doi.org/10.1016/j.jhydrol.2015.11.005.

Sun X., Xiang Y., Shi Z., 2018. Estimating the Hydraulic Parameters of a Confined Aquifer Based on the Response of Groundwater Levels to Seismic Rayleigh Waves. Geophysical Journal International 213 (2), 919-930. http:// dx.doi.org/10.1093/gji/ggy036.

Xiang Y., Sun X., Gao X., 2019. Different Coseismic Groundwater Level Changes in Two Adjacent Wells in a Fault-Intersected Aquifer System. Journal of Hydrology 578, 124123. https://doi.org/10.1016/j.jhydrol.2019.124123. 